\title{
Remarks On Richard Shusterman's Pragmatist Aesthetics
}

Krystyna Wilkoszewska

\section{CpenEdition}

Journals

Electronic version

URL: http://journals.openedition.org/ejpap/793

DOI: 10.4000/ejpap.793

ISSN: 2036-4091

\section{Publisher}

Associazione Pragma

\section{Electronic reference}

Krystyna Wilkoszewska, "Remarks On Richard Shusterman's Pragmatist Aesthetics », European Journal of Pragmatism and American Philosophy [Online], IV - 1 | 2012, Online since 23 July 2012, connection on 19 April 2019. URL : http://journals.openedition.org/ejpap/793 ; DOI : 10.4000/ ejpap.793

This text was automatically generated on 19 April 2019

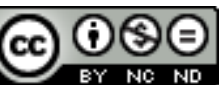

Author retains copyright and grants the European Journal of Pragmatism and American Philosophy right of first publication with the work simultaneously licensed under a Creative Commons AttributionNonCommercial-NoDerivatives 4.0 International License. 


\title{
Remarks On Richard Shusterman's Pragmatist Aesthetics
}

\author{
Krystyna Wilkoszewska
}

1 Owing largely to his influential work on pragmatist aesthetics and somaesthetics Richard Shusterman is one of the most renowned aestheticians in the world. The release of Pragmatist Aesthetics in 1992 greatly influenced the scholarly landscape; judging by the outpouring of translations, reviews, conference papers, $\mathrm{MA}$ and $\mathrm{PhD}$ theses written on related topics, indeed, one might say that the book inaugurated a new chapter in aesthetics. Shusterman's training as an analytic philosopher, and prior association with an analytic orientation in aesthetics, undoubtedly added to the book's appeal.

2 Shusterman is not the only philosopher to make a turn from the analytic to the pragmatist. Still, he is the only one to do so so radically, on such scale, and within the aesthetic domain. In Pragmatist Aesthetics he openly admits that his vision was largely inspired by the writings of John Dewey. Nonetheless, eight years later, in the preface to his book's second edition, the claim that "pragmatist aesthetics began with Dewey" seems too bold for Shusterman. He points to the early contributions of Ralph Waldo Emerson and Alain Locke, whose works were more or less directly known to Dewey; Dewey nonetheless omits mentioning Emerson and Locke as his, quite potent (according to Shusterman) sources of inspiration. Although it is impossible to deny aesthetic threads in the writings of the thinkers mentioned above, still, in my opinion they are not proof enough to weaken Dewey's leading role as the founder of pragmatist aesthetics.

3 Of the classical pragmatists, Dewey supplied the foundations for pragmatist aesthetics. His Art as Experience was published in 1934, yet for a number of reasons remained unnoticed during his lifetime. Firstly, pragmatism itself was at the time rather unpopular in Europe. Secondly, Dewey was no aesthetician, and his "philosophy of aesthetics" (his own term), returning art to real life and building fully on his own concept of experience, strongly opposed any acknowledged continental notions (such as the autonomy of the work of art or the uniqueness of an aesthetic experience). Dewey's aesthetic thought was continued on American soil, especially after his death in 1952, by followers foreshadowed by a dynamically developing analytic philosophy and aesthetics. Particularly the efforts 
of John McDermott, as well as Thomas Alexander and others, grouped in SAAP, are not to be underestimated. Within their works they not only strived to reconstruct Dewey's original ideas, but also to develop them, uncovering their hidden potential in emerging fields such as ecology, technology or urban design. Particularly important is McDermott's book The Culture of Experience (1976), which uses the basic assumptions of Dewey's (and James') philosophy of experience to show and diagnose the changes taking place in culture since the 1960s. These were changes of great proportions and radicalism, and when used for Deweyen-based aesthetic examination, they proved to be a most effective instrument, leading to conclusions that later emerged as highly accurate and significant. By way of example, we might mention here the role of touch and the whole sensory apparatus, as well as aesthetic sensibility, urban counsciousness, operativeness of environmental and contextual terms and a general return to everyday practices while discovering their aesthetic dimension. By taking advantage of an anti-fundamentalistic and anti-dualistic approach, McDermott's book constitutes a big step in the development of pragmatist aesthetics. ${ }^{1}$ Meanwhile in his preface to Pragmatist Aesthetics Shusterman writes: "Pragmatist aesthetics began with John Dewey - and almost ended there" and "the philosophical influence of his aesthetic theory was very short-lived. Pragmatist aesthetics was soon eclipsed and rejected by analytic aesthetics" (xvi). The words that follow (three lines later) may awake controversy: "This is not to deny important contributions by contemporary pragmatists to certain aesthetic issues - for example, Rorty on the ethical role of literature, and Margolis and Fish on interpretation." Indeed ${ }_{2}$ narrowing down contemporary pragmatist thinkers to post-analytic philosophers searching for inspiration in pragmatism seems a limiting perspective.

4 In his article on Bernstein, Roberto Frega stresses the still-evident tension between the philosophy of language and the philosophy of experience. ${ }^{2}$ Some, like Rorty, approaching pragmatism via analytic philosophy and postmodernism failed to acknowledge the importance of experience. Shusterman's progression also has its specificity, visible in extracts from his works. The author admits: "Pragmatism was not taught to me in Jerusalem or Oxford; nor did I teach it in the Negev. Philosophy there meant analytic philosophy, and aesthetics analytic aesthetics. Pragmatism emerged for me as a philosophical horizon only when I returned to America in $1985 .{ }^{\prime 3}$ This was the time of socalled neopragmatism in the States, with which Shusterman seems to have come in contact. In his article bearing the significant title "The End of the Aesthetic Experience" Shusterman names (apart from Dewey) Beardsley, Goodman and Danto (as well as Margolis and Rorty) as "the leading figures of the aesthetic tradition," who contributed to his own views on the subject. He adds: "While Dewey celebrated aesthetic experience, making it the very centre of his philosophy of art, Danto virtually shuns the concept." 4 His tense and dramatic intellectual transformation finally leads him to writing Pragmatist Aesthetics, where Shusterman definitely opts for the philosophy of experience.

5 A similar dramaturgy might be witnessed on the subject of interpretation. On his arrival at Temple, Shusterman encountered Joseph Margolis' concept of interpretation. He took part in discussions organized by the Institute on Interpretation, which shaped his understanding of interpretation. In "Pragmatist Aesthetics," one of the chapters is dedicated to the topic of "Pragmatism and Interpretation," another bears the title "Beneath Interpretation." Indeed, almost one fifth of the entire work is dedicated to the problem of interpretation. 
6 Pragmatist Aesthetics was translated into Polish in 1998 with omission, on the author's request, of the chapter "Pragmatism and Interpretation." In his preface to the Polish edition the author justified this decision as follows: "this translation, however more complete than any of the seven preceding it, does not contain one of the chapters present in the English original. It seemed too long, too technical to me, as well as containing too much internal tensions of pragmatists of the time." The omission of the chapter, however, led to half of the preface being dedicated to remarks on interpretation.

7 I could not assess whether the chapter was also omitted in other translations. I do not want to overestimate the importance of the Polish edition, but only to refer to it in making a more general point. The removal of the chapter may have a deeper importance. I believe that stressing the topic of interpretation in a work on pragmatist aesthetics is somehow misleading, given that the problem of interpretation is not one of the major issues of an aesthetics constructed on pragmatism (with its centralnotion of experience). Shusterman seems to be aware of this, yet it is not clear from which moment onwards. We are led to ask: (1) Was Shusterman already aware of this when writing Pragmatist Aesthetics and so decided to address his book to the American reader, and especially to analytic thinkers, taking into account their interest in the problem of interpretation? or (2) did he become aware years later (preparing the book for translation) that the problem of interpretation was not an integral part ofpragmatist aesthetics? This latter interpretation would prove that in a sense the author gradually freed himself from the burden of the tradition he was trained in.

8 In Art and Experience Dewey does not use the term "interpretation" at all. Shusterman introduces a whole chapter on interpretation to prove, as he himself writes, the value of pragmatism to both the analytic, as well as deconstructionist traditions - though this value is of a different kind. A pragmatist interpretation enables one to avoid extremes: the existence of an objective meaning that interpretation is only meant to discover, on the one hand, and the denial of such prior meaning (stripping the work of its own identity and leaving it open to a plurality of interpretations arising from contextually dependent linguisticgames) on the other.

9 I must admit I do not fully accept the strategy adopted by the author. Despite the fact that during the writing of Pragmatist Aesthetics analytic and deconstructionist orientations were dominant, this does not explain why regard for them had to be included in the construction of pragmatist aesthetics. The Deweyan concept of experience no doubt carries a potential that could inspire (also on the question on interpretation) the orientations Shusterman points to. Instead of considering the problem of interpretation in detail, within "pragmatist aesthetics" it would be more helpful to present all aspects and consequences of the pragmatist concept of experience.

10 Although the term "interpretation" hardly appears in Art and Experience, the term "interaction" may be found on nearly every page, as a fundamental characteristic of experience. Reconstruction is a form of interaction, which may take on an interpretative character. Both reconstruction and interpretation provoke a mutual subject-object transformation. In explaining the merit of pragmatist interpretation, Shusterman defines it as no so much discovering an existing sense but rather as giving sense. I am sceptical of this approach; interpreting is not giving, but merely co-shaping meanings. In an interaction of interpretative experience the subject is not fully in control, since the object resists. This renders the interaction a correlation of subject-object tensions, resulting in the transformation of subject and object, making them defined. Still, the author claims 
that the freedom of the subject is limited through the cultural education we receive, which makes us interpret works of art in specific, conventional ways. I want to stress once more - the way interaction takes its course and the layers of meaning it activates in the subject depend on the object and vice versa - what the subject discovers in the object depends on consecutive phases of an ongoing experience. Such experience is different each time, and so are its effects. It is even possible for the work of art's power to impel the interpreter into resigning his habits, or the subject'spower of habit and convention to block the works innovative character. To conclude, I will consider Shusterman's opinions in this context to be still determined by understanding interpretative experience as subject's experience.

11 In the second edition of Pragmatist Aesthetics (2000) the chapter on interpretation was not removed, and the newly added chapter, entitled "Somaesthetics: A Disciplinary Proposal" (similarly to the 1997 Practicing Philosophy. Pragmatism and the Philosophical Life) traces and develops somatic and sensual aspects of aesthetic experience present in Dewey's writings. In his preface to the second edition, the author addresses the reception his book received internationally, trying to counter the critical opinions received to this date. Amongst the themes discussed, the question of interpretation did not arise. This leads us to think that the relation of pragmatism and interpretation either did not cause any controversy, or the attempt to direct the interest of analytic and deconstructionist philosophy to pragmatism in this field has gone unnoticed. Be that as it may, the discussion over the book was dominated by doubts concerning the chapter on rap music, or, more precisely, the attitude of the author towards popular art. This was quite unfortunate for the book's reception, in my opinion, for the debate on rap foreshadowed important theses reshaping aesthetics according to pragmatist thought, which rap only served to exemplify. Instead, an attempt at attaching value to pop art resulted in excessive criticism, and the real value of Shusterman's book (consisting in the construction of a model of pragmatist aesthetics) was not sufficiently appreciated.

The author felt obliged to respond and explain the ongoing misunderstanding, devoting most of the preface to the second edition to popular artas well, an issue that does not seem the most essential to the project. This felt obligation proves how difficult it is for the pragmatist option in aesthetics to break through the habit of dualistic thinking, embedded so deeply in our tradition. For all that the author seeks to explain in the preface to the second edition was already present in the first. What is more, to reach his readers more effectively, the author settles on a commonly accepted explanatory procedure (binary logics). This in turn, in my opinion, undermines the idea of pragmatist thinking. And so, in trying to legitimize his benevolent outlook on popular art, and admitting it into the sphere of interest of contemporary aesthetics, to which pragmatist aesthetics complies due to its basic assumptions, the author succumbs to the temptation of using argumentation based on alternative of exclusion and that of inclusion. He does so to prove his deliberations were not aimed at exclusion (either of pop art or high-brow art) but at including both. The word "both" becomes essential. Even though the explanation will most probably serve its purpose, it is unfortunate that the author was forced to defend a statement clearly based on pragmatist convictions through the use of non-pragmatist language. Especially since his stance is fully clear even if not written into the dualistic matrix of opposites. Instead, conceptual oppositions are only hipostatized extremes of a polarised spectrum, where continuity and gradation, as well as the dynamics of change are impossible to apprehend within the framework of traditional 
logic. The demarcation between high-brow art and popular art loses its justification when faced with practice (and for pragmatist aesthetics this is essential).

In practice both the work of art andthe work that aspires to be art don't just belong to the category of fine art orthe category ofpopular art. They are located somewhere in between these two, having certain aspects closer to one or the other. The same applies to deep pleasure, traditionally linked to aesthetic experience, and shallow hedonistic pleasure. Argumentation grounded on including such alternatives would not be fully adequate here (we have a choice between one option and the other, or of even both, but the division remains explicit). If we were to use concepts of continuity and gradation, they would portray real-life cases more accurately, as the deepness of pleasure of experience is gradeable, sometimes, and sometimes only, adopting maximum polarisation.The fact of pragmatist aesthetics preferring the sphere of "between," as being closest to real-life praxis, over polar oppositions, deserves constant stress. To put it in Deweyan terms, nouns are all too often hipostases of adjectives, and these can be graded. If we were to grasp art in an adjectival way, the dilemma of whether something is or isn't a work of art gives way to the dilemma to what extent it is a work of art.

Twenty years have passed since the publication of Pragmatist Aesthetics. I wouldn't want to appear pessimistic, but I believe the understanding of this new approach, despite its popularity, has since progressed to just a small extent. ${ }^{5}$ This in turn means that the wearisome toil of explaining and setting things straight must be continued. I am confident that excessive attention the author devotes to interpretation, and readers devote to popular art, have distorted or foreshadowed the essential shape and importance of the "pragmatist aesthetics" project. A project contains as vital theses contrasting traditional aesthetics as theses concerning the aesthetic not standing in opposition to the practical, or the one stating that the task of aesthetic theory does not consist in describing the state of things but in meliorating human experience.

Looking back at these matters of reception may seem obsolete. Still, the book's twentieth anniversary may also become an occasion for reconsideration and retrospective. "Pragmatist Aesthetics" still remains the only work containing a full and comprehensive outline of what pragmatist aesthetics is. Perhaps it is time to consider a re-edition, unencumbered with the problems of the 80 s, and presenting an updated vision of pragmatist aesthetics fit for the 21st century.

\section{NOTES}

1. John S. Smith in the Foreword to McDermott's book The Culture of Experience wrote of the influence Dewey's Art as Experience had on McDermott's thought: 'He finds there ideas essential for understanding present dilemmas in culture and for reconstructing affective values which grow out of actual experience and are in no need of imposition from without'.

2. R. Frega, (2011), "Richard Bernstein and the challenges of the broadened pragmatism," European Journal of Pragmatism and American Philosophy, 3 (2). 
3. R. Shusterman (2000), Preface to Pragmatist Aesthetics. Living Beauty, Rethinking Art, Rowman and Littlefield Publishers, Inc., xvi, xvii

4. R. Shusterman (2000), The End of Aesthetic Experience. In: Performing Life. Aesthetic Alternatives for the Ends of Art, Cornell University Press, 15.

5. That is not the case with somaesthetics. Although it does constitute a part of pragmatist aesthetics, it tends to function independently. I get the impression Shusterman is now mostly renowned as the creator of somaesthetics, and it is no surprise why. Pragmatist aesthetics introduced solutions that strongly disrupted conventional aesthetic thinking. Somaesthetics also seemed highly innovative, but (quite fortunately) it was born during the period of strong bodily fascination, present on various levels of human activity, reaching from philosophical theory to everyday practice.

\section{AUTHOR}

\section{KRYSTYNA WILKOSZEWSKA}

Institute of Philosophy, Jagiellonian University

kw[at]iphils.uj.edu.pl 